\title{
Utilização de índices ecológicos em assembléias de peixes como instrumento de avaliação da degradação ambiental em programas de monitoramento
}

\author{
Fábio Flores-Lopes ${ }^{1,3}$, Mauricio Cetra ${ }^{2}$ \& Luiz Roberto Malabarba ${ }^{1}$ \\ ${ }^{1}$ Programa de Pós-graduação em Biologia Animal, Instituto de Biociências, Departamento de Zoologia, \\ Universidade Federal do Rio Grande do Sul - UFRGS, Av. Bento Gonçalves, n. 9500, prédio 43.435, \\ CEP 90540-000, Porto Alegre, RS, Brasil \\ ${ }^{2}$ Departamento de Ciências Biológicas, Universidade Federal de São Carlos - UFSCar, \\ Rod. João Leme dos Santos, Km 110, SP 264, CEP 18052-780, Sorocaba, SP, Brasil \\ ${ }^{3}$ Departamento de Ciências Biológicas, Universidade Estadual de Santa Cruz-UESC, \\ Rod. Ilhéus-Itabuna, Km 16, CEP 45662-000, Ilhéus, BA, Brasil \\ ${ }^{4}$ Autor para correspondência: Fábio Flores-Lopes, e-mail: fabiologo5@hotmail.com
}

FLORES-LOPES, F., CETRA, M. \& MALABARBA, L.R. Utilization of ecological indexes on assemblages of fish as instrument of assessment of the environmental degradation in monitoring programs. Biota Neotrop. 10(4): http://www.biotaneotropica.org.br/v10n4/en/abstract?article+bn03710042010.

\begin{abstract}
Several ecological indexes in taxocenoses of fish (constancy, diversity, richness, evenness, and integrated quality index - IQ) are used as indicators of environmental degradation through the analysis of standardized and seasonal fish samples taken along two years in eleven localities of the Lake Guaíba drainage. Localities that showed regular diversity indexes along two years are coincident with those with better environmental quality indicated by other factors (frequency of abnormalities in fishes, $\mathrm{DBO}_{5}$, temperature, total coliforms, dissolved oxygen). The integrated quality index, however, was mostly influenced by abundance and richness, being the localities indicated as the best quality by this index coincident with those indicated as bad quality by other factors. The accomplished analysis demonstrated that when the measure of water quality gets better, the Margalef Index decreases. This demonstrates that even having an improvement in water quality, there is no improvement of structure of the fish community of this place.
\end{abstract}

Keywords: environmental impact, integrated quality index, Guaíba Lake.

FLORES-LOPES, F., CETRA, M. \& MALABARBA, L.R. Utilização de índices ecológicos em assembléias de peixes como instrumento de avaliação da degradação ambiental em programas de monitoramento. Biota Neotrop. 10(4): http://www.biotaneotropica.org.br/v10n4/pt/abstract?article+bn03710042010.

Resumo: Este trabalho utiliza índices ecológicos em taxocenoses de peixes (constância de ocorrência, diversidade de espécies, riqueza, equitabilidade, índice de qualidade integrado (IQ)) como instrumento de avaliação da degradação ambiental. As amostragens foram padronizadas e realizadas sazonalmente durante dois anos, com rede de arrasto do tipo picaré, em onze pontos da bacia hidrográfica do lago Guaíba. Os pontos que apresentaram maior regularidade sazonal nos índices coincidem com locais de melhor qualidade ambiental indicados por outros fatores (frequência de anomalias, $\mathrm{DBO}_{5}$, temperatura, coliformes totais, oxigênio dissolvido). O cálculo do índice de qualidade integrado (IQ), entretanto, foi extremamente influenciado pela abundância e riqueza de espécies, sendo que os locais considerados de melhor qualidade por este índice correspondem aos de pior qualidade ambiental indicados por outros fatores. A análise realizada demonstrou que à medida que a qualidade da água melhora, $\mathrm{o}$ Índice de Margalef diminui. Isto demonstra que mesmo havendo uma melhora na qualidade da água, não houve uma melhora da estrutura da comunidade deste local.

Palavras-chave: impacto ambiental, índice de qualidade, Lago Guaíba. 


\section{Introdução}

Os ecossistemas naturais são sistemas complexos que estão sendo simultaneamente expostos a uma variedade de estressores (principalmente os ambientes aquáticos), cujos mecanismos e efeitos cumulativos são pobremente entendidos (Cairns et al. 1993). De acordo com Karr \& Dudley (1981), "um ecossistema pode ser considerado saudável quando seu potencial inerente é atingido, sua condição é estável, sua capacidade de auto-reparação quando perturbado é preservada e um suporte mínimo é exigido para seu manejo". Esta definição de ecossistema enfatiza a biota, mas ignora o uso dos parâmetros físicos e químicos do ecossistema, que podem operar independentemente dos parâmetros biológicos, mas do qual a biota pode ser dependente (Norris \& Thoms 1999). Os ecossistemas aquáticos estão sujeitos a modificações na qualidade das suas águas quando há um crescimento na indústria e na população, sem que haja um planejamento sustentável e controle do seu uso (Bruschi Jr. et al. 1998).

Os recursos hídricos são utilizados em todo mundo com diferentes objetivos que vão desde abastecimento doméstico, irrigação, geração de energia, navegação, aquicultura, harmonia paisagística, entre outros. Desta forma, atividades antrópicas têm exercido uma profunda influência sobre os ecossistemas aquáticos, afetando de forma significativa as populações de peixes de água doce (Cairns et al. 1993). A deterioração do ambiente, em função das atividades antrópicas, tem gerado necessidades de desenvolvimento e adequação de métodos de avaliação da qualidade ambiental. Uma avaliação efetiva das condições lóticas requer compreensão das múltiplas causas do estresse na biota aquática, incluindo a perda e degradação do habitat, a expansão de espécies exóticas, exploração desordenada, extinções secundárias, poluição por efluentes industriais e poluição por efluentes orgânicos e mudanças climáticas globais (Allan \& Flecker 1993).

Numa época onde as atividades antrópicas são as forças dominantes que influenciam as comunidades biológicas, um manejo apropriado requer o entendimento de processos e padrões no sistema biológico e o desenvolvimento de processos de taxação e avaliação que assegurem a proteção dos recursos biológicos (Karr 1987). Esta avaliação deve incluir o monitoramento biológico. O diagnóstico da integridade dos ecossistemas e a quantificação do grau de deterioração, juntamente com suas consequências sobre o ecossistema, tem sido um desafio permanente para os estudiosos da área ambiental (Bruschi Jr. et al. 2000). Os métodos biológicos que usam índices bióticos para expressar de forma numérica um conjunto de dados sobre a composição da fauna visando avaliar os efeitos da poluição nas comunidades aquáticas tem chamado a atenção dos cientistas e, quando utilizados para o monitoramento da qualidade da água, apresentam a vantagem de oferecer informações de efeitos ambientais prolongados (Lobo et al. 2002). Isto é, são capazes de refletir estados não mais existentes no momento da verificação, porém, originados a partir do processo de maturação da comunidade. Os Índices multimétricos bióticos estão sendo usados para complementar dados físicos e químicos em avaliações da qualidade de rios, desta forma facilitando uma avaliação mais compreensiva e acurada do ambiente (Angermeier \& Davideanu 2004).

Washington (1984) salientou que quando os índices multimétricos são aplicados nos ambientes aquáticos, espécies ou grupos de espécies de macroinvertebrados, peixes e diatomáceas podem ser utilizados como organismos indicadores. Este autor verificou que Margalef (1958) definiu "diversidade de espécies" como uma função do número de espécies presentes (riqueza de espécies ou abundância de espécies) e a equitabilidade como a proporção de indivíduos entre estas espécies (regularidade ou equitabilidade de espécies). Washington (1984), considerando a relevância para os ecossistemas em geral e para os sistemas aquáticos em particular e como os índices biológicos agora são comuns e usados em larga escala a fim de avaliar os efeitos de poluição, afirmou que há a necessidade de se examinar mais detalhadamente cada um dos muitos índices conhecidos como, por exemplo, os de diversidade e os de similaridade. Devem ser incluídos neste contexto o Índice de Integridade Biótica (IBI) e o Índice de Avaliação do Habitat (Vieira \& Shibatta 2007).

Os índices bióticos reúnem informações sobre vários atributos de uma comunidade biológica dentro de um número que reflete o status ecológico da comunidade. Um índice biótico leva em consideração a sensibilidade ou tolerância de uma espécie ou grupos de espécies à poluição e designa um valor, sendo que a soma destes valores resulta num índice de poluição para um determinado local. Os dados podem ser qualitativos (presença ou ausência) ou quantitativos (relativa abundância ou densidade absoluta) (Mason 1991). Entre os mais frequentes fatores estudados em sistemas lóticos estão aqueles relacionados ao declínio da qualidade química da água (e.g., pH, oxigênio dissolvido, nitrato, amônia e fosfato), perda física do habitat (e.g., largura e integridade da vegetação ripária, tipos de substrato, e diversidade de mesohabitats), e declínio da integridade biótica (e.g., presença de espécies exóticas, tolerantes ou reofílicas) (Karr \& Chu 1999). Karr (1981), Fausch et al. (1990), Araújo (1998a, b), Bruschi Jr. et al. (2000), Schiemer (2000) e Araújo et al. (2003) utilizaram a comunidade de peixes como indicadores de qualidade da água em programas de monitoramento ambiental.

Na Bacia hidrográfica do Lago Guaíba, poucos foram os estudos de monitoramento biológico realizados com peixes para verificar a integridade biótica do ambiente, principalmente com a utilização de espécies nativas. Estudos recentes com peixes neotropicais foram realizados por Rodríguez-Olarte et al. (2006) e Pinto et al. (2006). Dentre os estudos já desenvolvidos nesta bacia, podem ser citados os realizados por Flores-Lopes et al. (2001, 2002), Schulz $\&$ Martins-Junior (2001), Mollerke et al. (2002) e Malabarba et al. (2004), sendo que destes autores, apenas Malabarba et al. (2004) utilizaram o Índice de Constância como uma ferramenta para seleção de espécies indicadoras.

O objetivo deste trabalho foi avaliar a eficiência dos índices ecológicos em taxocenoses de peixes como uma ferramenta de avaliação da degradação ambiental em programas de monitoramento ambiental.

\section{Material e Métodos}

As amostragens de peixes foram realizadas sazonalmente por um período de dois anos, de dezembro de 2002 a outubro de 2004. O primeiro ano correspondeu ao período de dezembro de 2002 a outubro de 2003 no lago Guaíba e março 2003 a dezembro de 2003 nos rios tributários e o segundo ano de amostragem correspondeu de janeiro de 2004 a Dezembro de 2004 no lago Guaíba e de março de 2004 a dezembro de 2004 nos rios tributários.

Os peixes foram capturados com redes de arrasto do tipo picaré $(15 \mathrm{~m} \times 1.5 \mathrm{~m} \times 0.5 \mathrm{~cm})$ (Malabarba \& Reis 1987), em onze pontos da Bacia Hidrográfica do Lago Guaíba. Seis pontos foram no Lago Guaíba (Pt.1 - Gasômetro (30 02' 06,3" S e 51 14' 29,3” W), município de Porto Alegre; Pt.2 - Saco da Alemoa (29 59' 15,6” S e $51^{\circ} 14$ ' 24,1" W), município de Eldorado do Sul; Pt.3 - Foz do Arroio Celupa (30 06' 10" S e 51 $11^{\circ}$ ' 42,4" W), município de

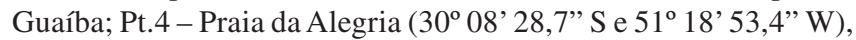
município de Guaíba; Pt.5 - Barra do Ribeiro (30 $17^{\prime} 11,4$ ”' S e $51^{\circ} 18^{\prime} 01^{\prime}$ W), município de Barra do Ribeiro e Pt.6 - Praia de Ipanema ( $30^{\circ} 08^{\prime} 03^{\prime}$ S e $\left.51^{\circ} 14^{\prime} 07^{\prime \prime} \mathrm{W}\right)$, município de Porto Alegre) e cinco pontos em três rios tributários. Destes cinco pontos, dois foram no Rio Caí; Pt.7 - próximo à ponte com a rodovia 


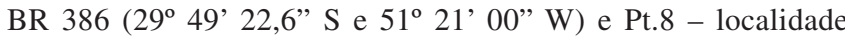
de Morretes ( $29^{\circ} 55^{\prime} 43,9^{\prime \prime} \mathrm{S}$ e $51^{\circ} 17^{\prime} 13,8^{\prime}$ ' W), próximo à foz com o Rio Jacuí, ambos no município de Nova Santa Rita), um no Rio dos Sinos - Pt.9 - junto à ponte com a rodovia BR 386 ( $29^{\circ} 52^{\prime} 36,5^{\prime \prime} \mathrm{S}$ e $51^{\circ} 14^{\prime} 35,4^{\prime}$ W), no município de Nova Santa Rita; dois no Rio Gravataí Pt.10 - junto à ponte com a rodovia

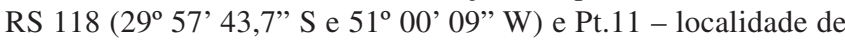
Passo das Canoas (29 57' 25,7' S e $51^{\circ} 00^{\prime} 23,2^{\prime}$ ' W), ambos no município de Gravataí (Figura 1).

Em cada ponto de coleta foram realizadas amostragens padronizadas com quatro arrastos de margem e os exemplares foram preservados em formalina a $10 \%$. No laboratório, o material coletado foi triado, identificado até o nível de espécie e preservado em álcool a $70 \%$.

Para análise dos dados, foram calculados os seguintes índices ecológicos: Constância de ocorrência (Dajoz 1983), sendo as espécies agrupadas nas seguintes categorias: espécies constantes - presentes em mais de 50\% das amostras; espécies acessórias - presentes em 25 a $50 \%$ das amostras e espécies acidentais - presentes em menos de $25 \%$ das amostras. Também foram calculados o Índice de Diversidade de Shannon \& Wiener Pielou (1975 apud Zar 1999), Riqueza de Espécies Margalef (1969 apud Zar 1999) e o Índice de Equitabilidade de Pielou (1975 apud Zar 1999). Todos estes índices foram calculados pelo programa Divers (versão 1.0) e efetuados sobre logaritmo natural. O teste $t$ para verificar o nível de significância dos índices de Diversidade entre os pontos estudados e com a sazonalidade foi calculado pelo programa Divert (versão 1.0).

O Índice de Qualidade Integrado (IQ) foi calculado como descrito em Bruschi Jr. et al. (2000). Para cálculo deste índice, foi utilizado o número total de indivíduos por local de amostragem, o número de espécies e o Índice de Diversidade. Estas três medidas foram transformadas em proporções de zero a um através da divisão de seus valores pelo maior valor obtido entre as amostras. Os resultados foram agrupados em intervalos de classe, para estabelecimento de categorias (alta, média e baixa qualidade), que foram estabelecidas realizando-se uma diminuição entre o valor máximo do valor mínimo, sendo o resultado dividido por três.

Uma análise de componentes principais foi realizada com os parâmetros temperatura, $\mathrm{pH}, \mathrm{DBO}_{5}, \mathrm{O}_{2}$ dissolvido e coliformes fecais com o objetivo de identificar quais desses parâmetros estavam influenciando na qualidade do corpo hídrico. Esta análise foi realizada através do software Multivariate Statistical Package v. 3.1. Os dados físicos e químicos dos pontos do Lago Guaíba foram fornecidos pelo DMAE (Departamento Municipal de Água e Esgoto). Os dados do Rio dos Sinos foram fornecidos pela FEPAM (Fundação Estadual de Proteção Ambiental). Os dados dos Rios Caí e Gravataí foram fornecidos pela CORSAN (Companhia Riograndense de Saneamento). A qualidade física e química da água foi verificada através do enquadramento da média dos valores obtidos para cada parâmetro dentro das classes estabelecidas pela resolução 357 do CONAMA. O estabelecimento da condição de referência foi baseado na identificação do local menos degradado (degradação física do habitat) e na melhor qualidade da água de acordo com a resolução 357 do CONAMA (Conselho... 2005). Os pontos de amostragem foram classificados em um gradiente de qualidade.

Uma ANOVA fatorial foi utilizada a fim de verificar se havia variação espacial e temporal. O Índice de Shannon foi utilizado como variável dependente. Os fatores utilizados foram ambientes (rio e lago) e estação (verão, outono, inverno e primavera). Uma análise de regressão linear foi utilizada a fim de verificar se havia correlação entre os Índices de Diversidade e Riqueza com o Índice de Qualidade Integrado (IQ) e a fim de validar os índices, os resultados dos mesmos foram correlacionados com os da análise de componentes principais e os parâmetros físicos e químicos da água.
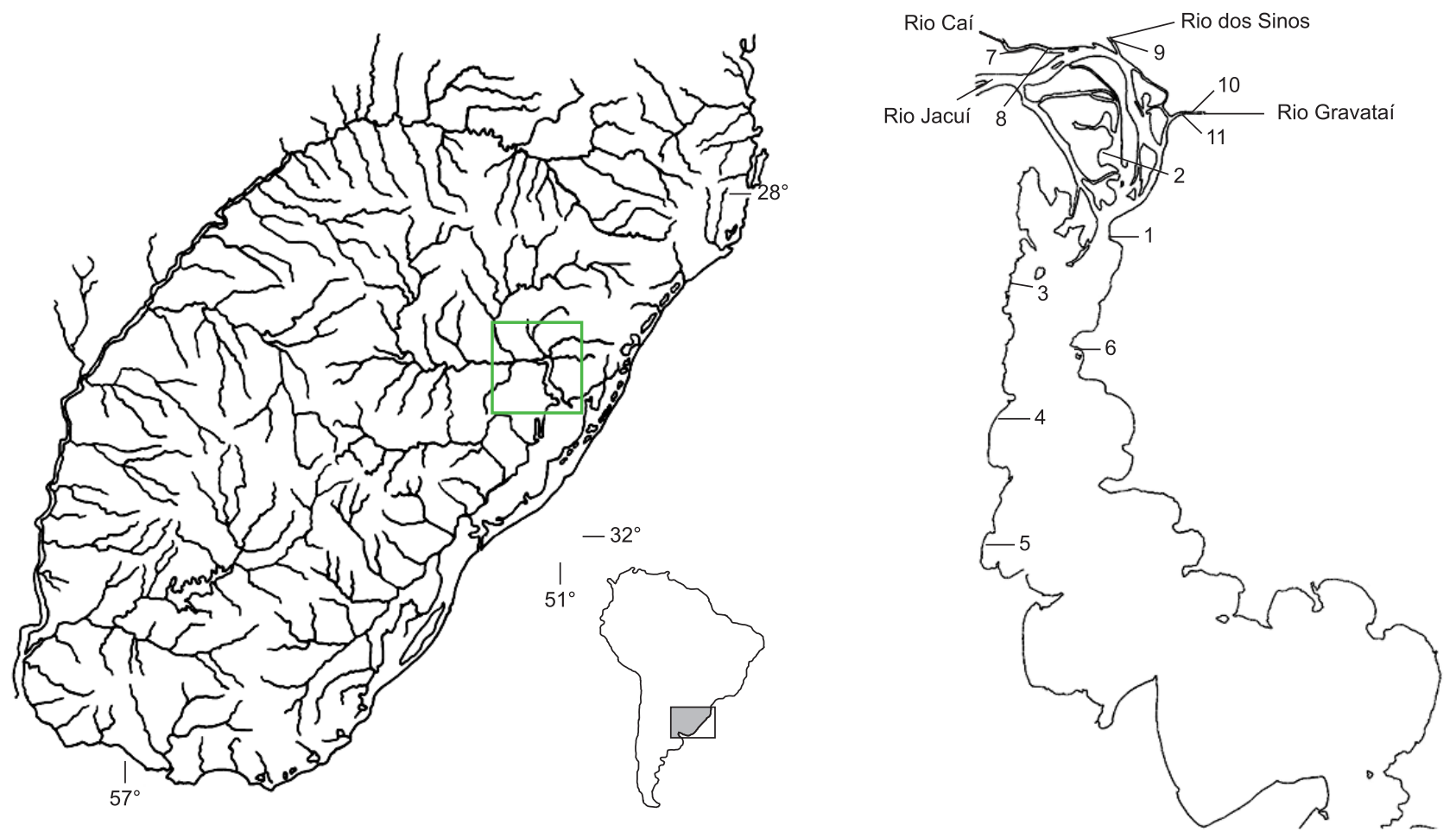

Figura 1. Mapa da bacia Hidrográfica do Lago Guaíba. No detalhe, mostrando os rios tributários e os locais de amostragem.

Figure 1. Map of the Lake Guaíba basin. In details, showing the flowing rivers and sampling spots. 
Flores-Lopes, F. et al.

\section{Resultados}

Foram capturados 53408 exemplares, sendo 24020 no Lago Guaíba e 29388 nos três rios tributários (Rios Caí, Sinos e Gravataí), de um total de 66 espécies pertencentes a 22 famílias e 8 ordens (Tabela 1). Do total de espécies identificadas, 52 delas foram observadas no Lago Guaíba e 58 foram observadas nos rios tributários. A análise da composição da ictiofauna mostrou que as ordens mais abundantes foram Characiformes (43\%), Siluriformes $(30 \%)$ e Perciformes (14\%). As famílias mais abundantes foram Characidae (29\%), Loricariidae e Cichlidae (12\%) e as espécies mais abundantes foram Cheirodon ibicuhiensis Eigenmann, 1915 (21,7\%), Astyanax fasciatus (Cuvier, 1819) (20,5\%), Hyphessobrycon luetkenii (Boulenger, 1887) (15,5\%) e Corydoras paleatus (Jenyns, 1842) (11\%).

As espécies consideradas constantes foram: Cyanocharax alburnus (Hensel, 1870) (95,45\%), Astyanax fasciatus (90,90\%), Astyanax jacuhiensis Cope, 1894 (85,22\%), Rineloricaria cadeae (Hensel, 1868) (62,50\%), Gymnogeophagus gymnogenys (Hensel, 1870) (60,22\%), Cyphocharax voga (Hensel, 1870) (59,09\%), Hyphessobrycon luetkenii (59,09\%) e Corydoras paleatus (50\%). As espécies Characidium tenue (Cope, 1894), Diapoma speculiferum Cope, 1894, Gymnotus carapo Linnaeus, 1758, Hoplosternum littorale (Hancock, 1828), Hyphessobrycon sp., Hypostomus commersoni Valenciennes, 1836, Parapimelodus nigribarbis (Boulenger, 1889) e Tilapia rendalli (Boulenger, 1897) foram observadas somente no Lago Guaíba e as espécies Ancistrus brevipinnis (Regan, 1904), Astyanax sp. 2, Bunocephalus doriae Boulenger, 1902, Charax stenopterus (Cope, 1894), Corydoras undulatus Regan, 1912, Cynopoecilus nigrovittatus Costa, 2002, Cynopoecilus melanotaenia Regan, (1912), Hyphessobrycon meridionalis Ringuelet, Miquelarena \& Menni, 1978, Prochilodus lineatus (Valenciennes, 1836), Rhamdia aff. Quelen (Quoy \& Gaimard, 1824), Rineloricaria sp. n e Schizodon jacuiensis Bergman, 1988 foram observadas exclusivamente nos rios tributários. Os pontos que apresentaram o maior percentual de indivíduos coletados foram o Gravataí PC - Pt.11 (31\%), Gasômetro - Pt.1 (23\%), Gravataí RS118 - Pt.10 (11\%) e S. Alemoa - Pt.2 $(10 \%)$.

As maiores diversidades no Lago Guaíba foram observadas no ponto F. Celupa $(2,16)$, em outubro 2004, e no ponto S. Alemoa $(1,92)$, em Abril 2004. Neste ambiente, o ponto B. Ribeiro foi o que apresentou valores de diversidade mais regulares (Figura 2a) e o maior valor do Índice de Riqueza (3,02), em julho de 2003 (Figura 3a). O maior Índice de Equitabilidade foi observado no ponto $\mathrm{S}$. Alemoa $(0,84)$ em Abril de 2004.

Nos rios, as maiores diversidades foram observadas no ponto Sinos $(2,28)$, em Setembro de 2004, e no ponto Gravataí PC $(2,24)$, em Setembro de 2003 (Figura 2b). Este ponto apresentou os valores de diversidade mais regulares (Figura $2 b$ ). $\mathrm{O}$ índice de riqueza mais elevado foi observado no ponto Sinos (4,20), em Setembro de 2004 (Figura 3b) e o Índice de equitabilidade mais elevado foi observado no ponto Caí $(0,83)$, em Dezembro de 2004.

O teste $t$ aplicado para comparar os valores dos índices de diversidade em relação à sazonalidade, mostrou que $68,18 \%$ das combinações foram estatisticamente significativas. O mesmo tipo de comparação foi realizado isoladamente dentro de cada ponto de amostragem, mostrando os seguintes resultados: Gasômetro 78,57\%; Saco da Alemoa - 75\%; Foz do Celupa - 64,28\%; Praia da Alegria - 78,57\%; Barra do Ribeiro - 46,42\%; Praia de Ipanema 71,42\%; Rio Caí - 21,42\%; Rio Caí-Jacuí - 78,57\%; Rio dos Sinos - 60,71\%; Gravataí RS118 - 85,71\% e Gravataí PC - 89,28\%. A comparação entre os índices de diversidade totais mostrou que $94,54 \%$ das combinações eram estatisticamente significativas.

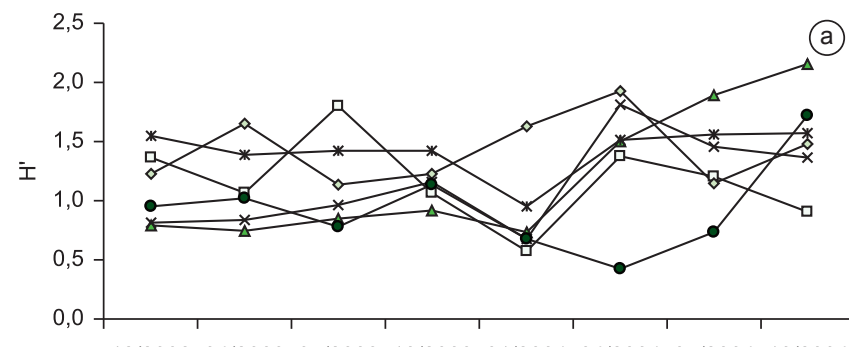

12/2002 04/2003 07/2003 10/2003 01/2004 04/2004 07/2004 10/2004 Período de amostragem

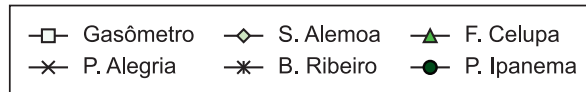

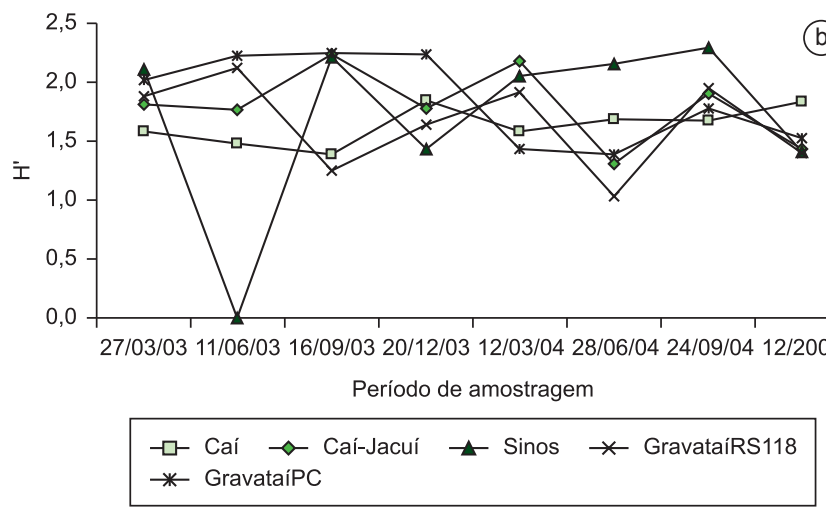

Figura 2. Variação sazonal do Índice de Diversidade observado ao longo do período de amostragem. a) Lago Guaíba; e b) rios Caí, Sinos e Gravataí.

Figure 2. Seasonal variation of the diversity index observed along samples. a) lake Guaíba; and b) Caí, Sinos and Gravataí rivers.
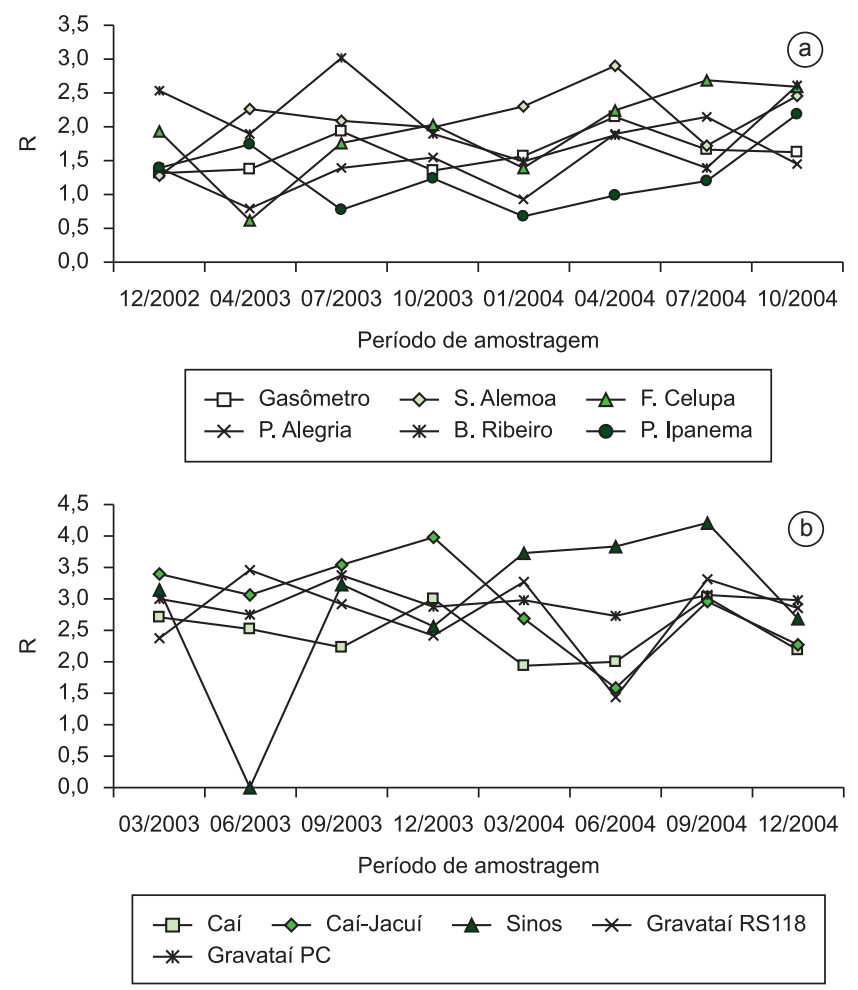

Figura 3. Variação sazonal do Índice de Riqueza de espécies observado ao longo do período de amostragem. a) Lago Guaíba; e b) Rios Caí, Sinos e Gravataí.

Figure 3. Seasonal variation of the species richness index observed along samples. a) Lake Guaíba; and b) Caí, Sinos and Gravataí rivers. 
Tabela 1. Lista de espécies capturadas na bacia hidrográfica do Lago Guaíba durante o período de amostragem. $\mathrm{n}$ = número de indivíduos; IC = Índice de Constância.

Table 1. List of the species captured in the drainage of lake Guaíba during fieldwork. $\mathrm{n}=$ number of individuals; IC $=$ Constancy Index.

\begin{tabular}{|c|c|c|c|}
\hline Família & Espécies & $\mathbf{n}$ & IC $(\%)$ \\
\hline Anablepidae & Jenynsia multidentata (Jenyns, 1842) & 105 & 18.18 \\
\hline \multirow[t]{2}{*}{ Anostomidae } & Leporinus obtusidens (Valenciennes, 1836) & 2 & 2.27 \\
\hline & Schizodon jacuiensis Bergman, 1988 & 3 & 2.27 \\
\hline \multirow[t]{2}{*}{ Aspredinidae } & Bunocephalus doriae Boulenger, 1902 & 13 & 1.13 \\
\hline & Bunocephalus iheringii Boulenger, 1891 & 28 & 15.90 \\
\hline Atherinopsidae & Odontesthes aff. perugiae Evermann \& Kendall, 1906 & 35 & 18.18 \\
\hline \multirow[t]{3}{*}{ Callichthyidae } & Corydoras paleatus (Jenyns, 1842) & 5871 & 50.00 \\
\hline & Corydoras undulatus Regan, 1912 & 1 & 1.13 \\
\hline & Hoplosternum littorale (Hancock, 1828) & 1 & 1.13 \\
\hline \multirow[t]{23}{*}{ Characidae } & Aphyocharax anisitsi Eigenmann \& Kennedy, 1903 & 54 & 18.18 \\
\hline & Astyanax eigenmanniorum (Cope, 1894) & 37 & 4.54 \\
\hline & Astyanax fasciatus (Cuvier, 1819) & 10955 & 90.90 \\
\hline & Astyanax jacuhiensis Cope, 1894 & 3226 & 85.22 \\
\hline & Astyanax sp. 1 & 25 & 2.27 \\
\hline & Astyanax sp. 2 & 4 & 1.13 \\
\hline & Bryconamericus iheringii (Boulenger, 1887) & 185 & 23.86 \\
\hline & Characidium rachovii Regan, 1913 & 1 & 1.13 \\
\hline & Characidium tenиe (Cope, 1894) & 346 & 30.68 \\
\hline & Characidium zebra Eigenmann, 1909 & 40 & 6.81 \\
\hline & Charax stenopterus (Cope, 1894) & 6 & 2.27 \\
\hline & Cheirodon ibicuihensis Eigenmann, 1915 & 11601 & 39.77 \\
\hline & Cheirodon interruptus (Jenyns, 1842) & 25 & 4.54 \\
\hline & Cyanocharax alburnus (Hensel, 1870) & 3257 & 95.45 \\
\hline & Diapoma speculiferum Cope, 1894 & 1 & 1.13 \\
\hline & Hyphessobrycon bifasciatus Ellis, 1911 & 11 & 5.68 \\
\hline & Hyphessobrycon luetkenii (Boulenger, 1887) & 8297 & 59.09 \\
\hline & Hyphessobrycon meridionalis Ringuelet, Miquelarena \& Menni, 1978 & 1 & 1.13 \\
\hline & Hyphessobrycon sp. & 1 & 1.13 \\
\hline & Oligosarcus jenynsii (Günther, 1864) & 41 & 12.50 \\
\hline & Oligosarcus robustus Menezes, 1969 & 157 & 40.90 \\
\hline & Pseudocorynopoma doriae Perugia, 1891 & 654 & 35.22 \\
\hline & Serrapinnus calliurus (Boulenger, 1900) & 926 & 40.90 \\
\hline \multirow[t]{8}{*}{ Cichlidae } & Cichlasoma portalegrense (Hensel, 1870) & 4 & 4.54 \\
\hline & Crenicichla lepidota Heckel, 1840 & 21 & 13.63 \\
\hline & Crenicichla punctata Hensel, 1870 & 53 & 22.72 \\
\hline & Geophagus brasiliensis (Quoy \& Gaimard, 1824) & 430 & 36.36 \\
\hline & Gymnogeophagus gymnogenys (Hensel, 1870) & 911 & 60.22 \\
\hline & Gymnogeophagus labiatus (Hensel, 1870) & 124 & 25.00 \\
\hline & Gymnogeophagus rhabdotus (Hensel, 1870) & 115 & 11.36 \\
\hline & Tilapia rendalli (Boulenger, 1897) & 1 & 1.13 \\
\hline Clupeidae & Platanichthys platana (Regan, 1917) & 57 & 17.04 \\
\hline \multirow[t]{2}{*}{ Curimatidae } & Cyphocharax spilotus (Vari, 1987) & 487 & 27.27 \\
\hline & Cyphocharax voga (Hensel, 1870) & 950 & 59.09 \\
\hline Engraulidae & Lycengraulis grossidens (Spix \& Agassiz, 1829) & 384 & 24.80 \\
\hline Erythrinidae & Hoplias malabaricus (Bloch, 1794) & 43 & 20.45 \\
\hline Gymnotidae & Gymnotus carapo (Linnaeus, 1758) & 1 & 1.13 \\
\hline \multirow[t]{2}{*}{ Heptapteridae } & Pimelodella australis Eigenmann, 1917 & 527 & 37.50 \\
\hline & Rhamdia aff. quelen (Quoy \& Gaimard, 1824) & 7 & 3.40 \\
\hline
\end{tabular}


Flores-Lopes, F. et al.

Tabela 1. Continuação...

\begin{tabular}{|c|c|c|c|}
\hline Família & Espécies & n & IC $(\%)$ \\
\hline \multirow[t]{9}{*}{ Loricariidae } & Ancistrus brevipinnis (Regan, 1904) & 3 & 1.13 \\
\hline & Hisonotus sp. & 88 & 19.31 \\
\hline & Hypostomus aspilogaster (Cope, 1894) & 92 & 10.22 \\
\hline & Hypostomus commersoni Valenciennes, 1836 & 7 & 3.40 \\
\hline & Loricariichthys anus (Valenciennes, 1836) & 35 & 17.04 \\
\hline & Otocinclus flexilis Cope, 1894 & 848 & 22.72 \\
\hline & Rineloricaria cadeae (Hensel, 1868) & 1239 & 62.50 \\
\hline & Rineloricaria sp. & 1 & 1.13 \\
\hline & Rineloricaria strigilata (Hensel, 1868) & 230 & 40.90 \\
\hline \multirow[t]{2}{*}{ Pimelodidae } & Parapimelodus nigribarbis (Boulenger, 1889) & 624 & 10.22 \\
\hline & Pimelodus maculatus La Cepède, 1803 & 15 & 11.36 \\
\hline Poecilidae & Phalloceros caudimaculatus (Hensel, 1868) & 6 & 4.54 \\
\hline Prochilodontidae & Prochilodus lineatus (Valenciennes, 1836) & 1 & 1.13 \\
\hline Pseudopimelodidae & Microglanis cottoides (Boulenger, 1891) & 2 & 2.27 \\
\hline \multirow[t]{2}{*}{ Rivulidae } & Cynopoecilus nigrovittatus Costa, 2002 & 1 & 1.13 \\
\hline & Cynopoecilus melanotaenia (Regan, 1912) & 1 & 1.13 \\
\hline Sciaenidae & Pachyurus bonariensis Steindachner, 1879 & 162 & 27.27 \\
\hline Trichomycteridae & Homodiaetus anisitisi Eigenmann \& Ward, 1907 & 28 & 10.22 \\
\hline Total & & 53408 & \\
\hline
\end{tabular}

Os maiores valores do Índice de Qualidade Integrado (IQ) calculado para o Lago Guaíba foram observados no ponto Gasômetro, em dezembro de $2002(3,0)$ e no ponto S. Alemoa, em julho de 2004 $(2,8)$ (Figura 4a). Os resultados para todo o período de dois anos de amostragem mostraram que os pontos Gasômetro e S. Alemoa foram classificados como de alta qualidade ambiental, os pontos F. Celupa e B. Ribeiro como de média qualidade e os pontos P. Alegria e P. Ipanema foram classificados como de baixa qualidade (Tabelas 2 e 3). Os maiores valores de IQ calculado para os Rios Caí, Sinos e Gravataí foram observados no ponto Gravataí PC, em junho de 2003 $(3,0)$ e no ponto Caí-Jacuí, em março de 2003 (2,8) (Figura 4b). Os resultados mostraram que o ponto Gravataí PC foi classificado como de alta qualidade ambiental, os pontos Caí-Jacuí e Gravataí RS118 de média qualidade e os pontos Caí e Sinos foram classificados como de baixa qualidade (Tabelas 4 e 5).

A análise multivariada demonstrou dois eixos que explicam os parâmetros utilizados neste estudo. $\mathrm{O}$ eixo 1 explica as variáveis $\mathrm{pH}, \mathrm{DBO}_{5}$ e $\mathrm{O}_{2}$ e o eixo 2 explica as variáveis coliformes fecais e temperatura (Tabela 6).

O ponto B. Ribeiro foi considerado como o de melhor qualidade da água em toda a bacia devido a sua elevada média de $\mathrm{O}_{2}$ e média mais baixa de coliformes fecais e $\mathrm{DBO}_{5}$. As localidades S. Alemoa, F. Celupa, P. Alegria e P. Ipanema mostraram qualidade mais baixa do que o ponto B. Ribeiro, variando de boa para razoável durante o período de amostragem. As maiores variações de temperatura foram observadas nos pontos F. Celupa e B. Ribeiro. O ponto P. Ipanema apresentou uma qualidade razoável da água, que variou de boa a razoável durante o período de amostragem. Os pontos Gasômetro, Caí, Caí-Jacuí e Sinos foram os que apresentaram a pior qualidade. Isto se deveu a médias mais baixas de $\mathrm{O}_{2}$ e as médias mais elevadas de coliformes fecais e $\mathrm{DBO}_{5}$. Uma pequena variação na temperatura e uma alta variação no $\mathrm{pH}$ foram observadas nestes pontos. $\mathrm{O}$ ponto Gasômetro pode ser considerado como o de pior qualidade devido à elevada média de coliformes fecais e $\mathrm{DBO}_{5}$ e uma baixa média de $\mathrm{O}_{2}$ durante todo o período de amostragem. A variação de temperatura observada nestes pontos foi muito pequena.

O ponto B. Ribeiro foi classificado como Classe I, para os parâmetros analisados, de acordo com a resolução 357 do CONAMA. As localidades S. Alemoa, F. Celupa, P. Alegria e P. Ipanema foram classificadas como classe I para $\mathrm{pH}, \mathrm{O}_{2}$ e $\mathrm{DBO}_{5}$. Para a presença de coliformes fecais, o ponto $\mathrm{S}$. Alemoa foi classificado como classe IV, o ponto F. Celupa foi classificado como classe II e o ponto P. Alegria foi classificado como classe III.

Os pontos Gasômetro, Caí, Caí-Jacuí e Sinos foram classificados como classe IV para coliformes fecais e Classe I para os outros parâmetros. Os pontos Gravataí RS118 e Gravataí PC apresentaram uma qualidade razoável, sendo classificados como classe I para $\mathrm{O}_{2}$, $\mathrm{pH}$ e $\mathrm{DBO}_{5}$ e classe II para coliformes fecais.

Dentre todas as combinações realizadas entre os valores dos eixos 1 e 2, obtidos pela PCA, e os valores do Índice de Qualidade Integrado (IQ), Índice de Diversidade, Índice de Margalef e Índice de Equitabilidade, somente as combinações entre o eixo 1 e o Índice de Margalef foram consideradas estatisticamente significativas $(n=88$, $\mathrm{r}=0,1432$ e $\mathrm{p}=0,0002$ ) (Figura 5). Estes resultados demonstraram que à medida que melhora a qualidade da água, reduz o Índice de Margalef. Foi observado que, independente do ambiente, os valores de diversidade na primavera foram mais elevados $(p=0,055)$ do que aqueles observados no verão (Figura 6). Além disto, a diversidade de espécies dos rios é mais significativa $(\mathrm{p}<0,001)$ do que no lago, demonstrando um valor médio mais elevado (Figura 7).

\section{Discussão}

Autores como Lobo et al. (2002), Bruschi Jr. et al. (2000), Ferreira e Casatti (2006) e Cetra et al. (2009) tem salientado que, normalmente, os elevados resultados dos índices de diversidade estão associados a uma melhor qualidade ambiental, o que também foi verificado neste estudo, sendo que as localidades F. Celupa e Sinos mostraram os valores mais elevados do Índice de Diversidade 
Tabela 2. Valores obtidos através do Índice de Qualidade Integrado para o Lago Guaíba. n = número de indivíduos; $\mathrm{s}=$ número de espécies; H’ = Índice de Diversidade de Shannon-Wiener e IQ = Índice de Qualidade Integrado.

Table 2. Values obtained through the Integrated Index of Quality for lake Guaíba. $n=$ number of individuals; $s=$ number of species; H' = Diversity Index of Shannon-Wiener and IQ = Integrated index of quality.

\begin{tabular}{lccccrr}
\hline Total & Gasômetro & S. Alemoa & F. Celupa & P. Alegria & B. Ribeiro & P. Ipanema \\
\hline N & 12068 & 5369 & 960 & 1291 & 2453 & 1879 \\
S & 30 & 34 & 29 & 22 & 1.52672 & 1.80529 \\
H' & 1.43595 & 1.7795 & 1.84144 & & & \\
& & & & & & \\
n/12068 & 1 & 0.444896 & 0.079549 & 0.106977 & 0.203265 & 0.155701 \\
s/38 & 0.789474 & 0.894737 & 0.763158 & 0.578947 & 1 & 0.473684 \\
H'/1.84144 & 0.779797 & 0.966363 & 1 & 0.82909 & 0.980369 & 0.776631 \\
IQ & 2.569271 & 2.305996 & 1.842707 & 1.515015 & 2.183633 \\
\hline
\end{tabular}

Tabela 3. Classificação dos pontos de amostragem do Lago Guaíba de acordo com os valores do Índice de Qualidade Integrado.

Table 3. Classification of lake Guaíba's sampling spots through the values of the quality index.

\begin{tabular}{lll}
\hline \multicolumn{1}{c}{ Qualidade } & \multicolumn{1}{c}{ Int. classe (IQ) } & Pontos \\
\hline Baixa & $1.406017-1.7937683$ & P. Alegria e P. Ipanema \\
Intermediária & $1.7937684-2.1815197$ & F. Celupa e B. Ribeiro \\
Alta & $2.1815198-2.5692711$ & Gasômetro e S. Alemoa \\
\hline
\end{tabular}
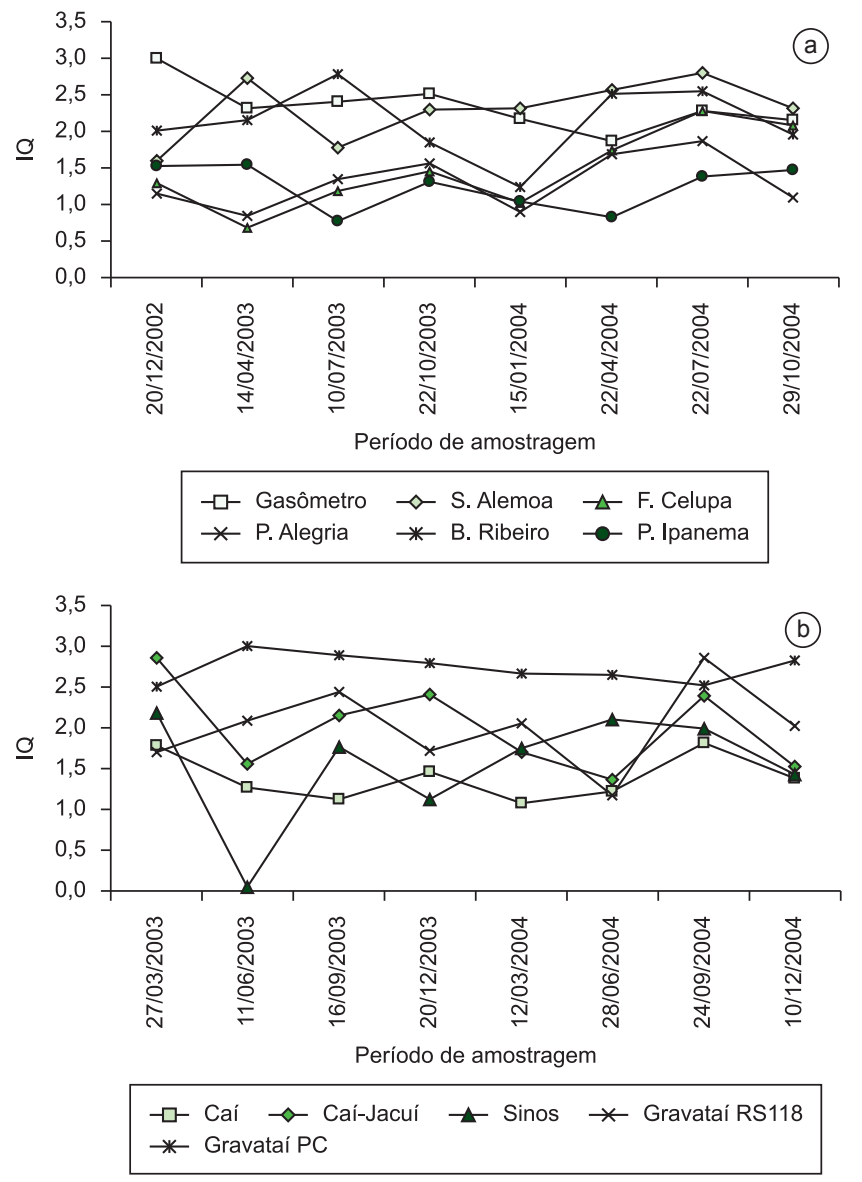

Figura 4. Variação Sazonal do Índice de Qualidade Integrado (IQ) observado durante o período de amostragem. a) Lago Guaíba; e b) Rios Caí, Sinos e Gravataí.

Figure 4. Seasonal variation of the integrated index of quality observed along samples. a) lake Guaíba; and b) Caí, Sinos and Gravataí Rivers. e os pontos B. Ribeiro e Sinos apresentaram valores mais elevados de riqueza de espécies, e ainda os pontos B. Ribeiro e Gravataí PC apresentaram uma maior regularidade nos Índices de Diversidade ao longo das amostragens, indicando que ambos demonstraram a melhor qualidade ambiental. Bendati et al. (1998), salientaram que índices de diversidade podem mostrar altas diversidades onde a qualidade do ambiente é pobre. Estas observações salientam que os índices não são as melhores ferramentas a serem utilizadas em programas de monitoramento ambiental e reforçam a necessidade da utilização de várias metodologias diferentes a fim de se obter uma avaliação mais acurada sobre os efeitos antropogênicos que estão atuando em um determinado local.

Os resultados obtidos pelos índices concordam em parte com os verificados pela análise física e química e pelo enquadramento em classes de qualidade (resolução 357 do CONAMA), uma vez que o ponto B. Ribeiro demonstrou apresentar a melhor qualidade da água em função de serem verificadas as médias mais elevadas de oxigênio dissolvido e as médias mais baixas de coliformes fecais. Flores-Lopes (2006) também observou, nos mesmos pontos, uma elevada frequência de infecção por parasitos trematódeos digenéticos, que provocam a doença dos pontos pretos, e correlacionou estas altas frequências de parasitos com a melhor qualidade ambiental.

Os pontos Gasômetro, S. Alemoa e Gravataí PC foram considerados como de alta qualidade pelo Índice de Qualidade Integrado (IQ), sendo que os resultados obtidos por este teste são fortemente influenciados pela abundância e riqueza de espécies observada nestas localidades. Os pontos Gasômetro e S. Alemoa, durante todo o período de estudo, não mostraram regularidade do Índice de Diversidade, sendo o ponto Gasômetro considerado como de baixa qualidade ambiental por este parâmetro. Este resultado é semelhante ao observado por Flores-Lopes (2006) e Malabarba et al. (2004), que observaram uma elevada frequência de alterações morfológicas em peixes nesta localidade. Além disso, Flores-Lopes (2006) observou ainda neste ponto uma elevada frequência de alterações moderadas e severas nas brânquias de Astyanax fasciatus e Cyanocharax alburnus, médias mais baixas de oxigênio dissolvido e médias elevadas de coliformes fecais.

Os resultados deste estudo demonstraram que à medida que aumenta a qualidade da água, reduz o Índice de Margalef, indicando que não há uma melhora na estrutura da comunidade nestes pontos. Isto pode ser verificado pela dominância de espécies como Astyanax fasciatus, Astyanax jacuhiensis, Cyanocharax alburnus e Hyphessobrycon luetkenii, consideradas como generalistas por Bruschi Jr. et al. (2000) em relação as demais, sendo observadas nos pontos mais degradados. Vieira \& Shibatta (2007), estudando o Ribeirão Esperança, também verificaram uma redução da riqueza de espécies com o aumento da qualidade ambiental. Para estes autores, 
Flores-Lopes, F. et al.

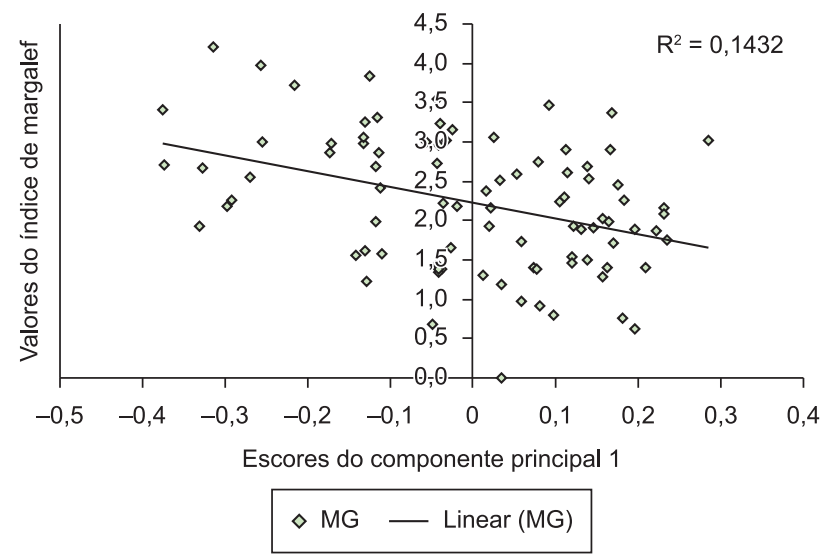

Figura 5. Correlação Linear entre o eixo 1 e o Índice de Margalef.

Figure 5. Linear correlation between axi one and Margalef index.

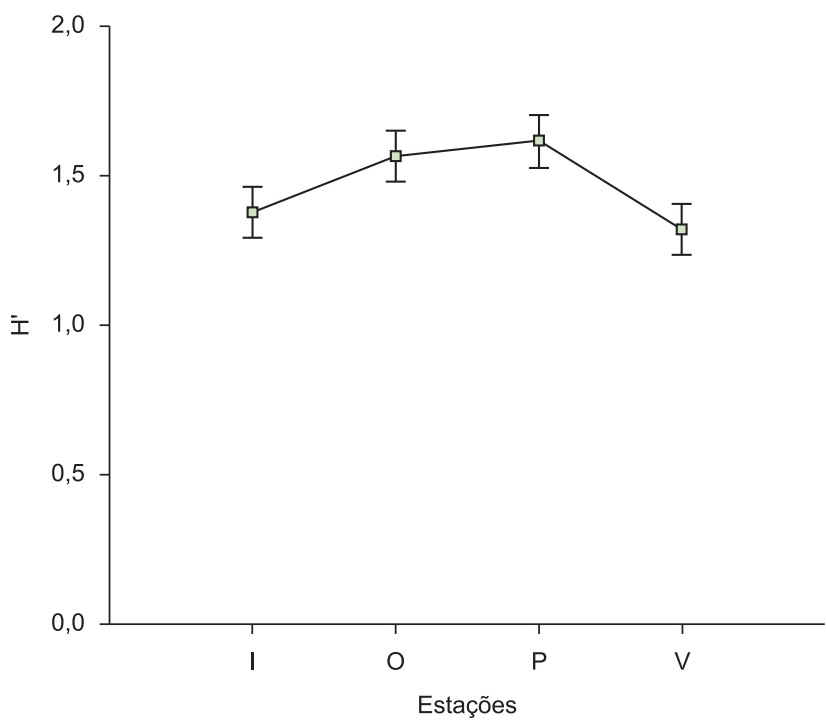

Figura 6. Valores médios do Índice de Diversidade de Shannon com erro padrão (E). Inverno (I), Outono (O), Primavera (P) e verão (V).

Figure 6. Middle values of the Shannon diversity índex with the standard error (I).Winter (W), Autumn (A), Spring (Sp) and Summer (S).

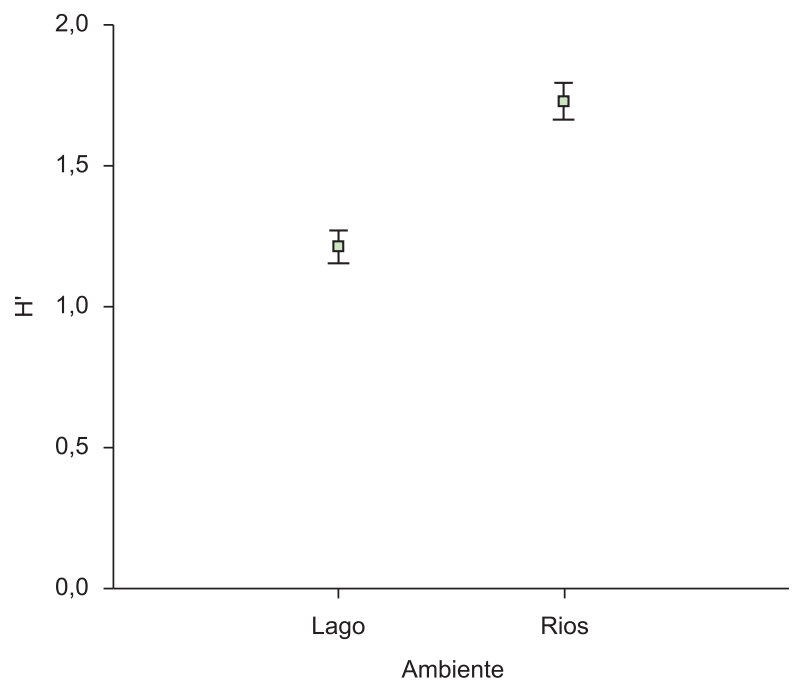

Figura 7. Valores médios do Índice de Diversidade de Shannon com erro padrão (I).

Figure 7. Middle values of Shannon diversity índex with standard error (I). este fato pode estar relacionado com as características físicas, a presença de espécies exóticas e resistentes a alterações ambientais e a dominância das espécies Poecilia reticulata e Hypostomus ancistroides.

Bruschi Jr. et al. (2000) mostraram que a ocorrência de espécies generalistas corrobora a classificação de locais de qualidade intermediária ou baixa e Pinto et al. (2006), estudando a análise física e química do Rio Paraíba do Sul, observaram que todos os pontos estudados tinham características de boa qualidade da água, embora a área de estudo incluísse os trechos mais urbanizados e industrializados do rio, sendo considerada a área mais impactada. Estes autores observaram que as condições da qualidade da água parece ser a maior barreira para a distribuição de espécies de peixes sensíveis e a ocorrência de um número elevado de espécies oportunistas em locais poluídos do que em locais não poluídos. Eles observaram que a assembléia de peixes no Rio Paraíba do Sul é composta principalmente por espécies como Poecilia reticulata, Geophagus brasiliensis e Tilapia sp., que são introduzidas e adaptadas a ambientes alterados.

Mason (1991) salientou que os índices consideram que os ambientes não poluídos são compostos por um grande número de espécies, sendo que nenhuma delas representa a maioria da comunidade, enquanto os ambientes poluídos são compostos por poucas espécies e algumas delas representam a maioria da comunidade. Neste estudo, o teste de ANOVA não paramétrica demonstrou que o ambiente de cada um dos rios apresentava uma diversidade mais significativa do que o Lago Guaíba, sendo esta diversidade mais elevada na primavera do que no verão. Estes resultados estão de acordo com os obtidos pela análise multivariada, que demonstrou que os pontos dos rios apresentavam uma melhor qualidade ambiental do que os pontos do Lago Guaíba. O fato de ser observada uma diversidade mais elevada na primavera do que no verão, provavelmente está relacionado com o ciclo reprodutivo da maioria das espécies, que começa na primavera e estende-se até o verão, o que pode ser comprovado pelos estudos realizados por Azevedo et al. (2010), Gelain et al. (1999) e Oliveira et al. (2002), ao estudarem varias espécies da região sul do Brasil.

Pinto et al. (2006), estudando a proximidade de uma planta industrial sobre a assembléia de peixes do Rio Paraíba do Sul, verificaram que a análise das curvas de abundância-biomassa e K-dominância confirmaram a associação de uma baixa diversidade a pior qualidade da água em função de fatores físicos e químicos. Para eles, o uso de indicadores biológicos fornece uma resposta melhor em relação à degradação ambiental do que as medições liminológicas tradicionais. Para Metcalfe (1989), medições físicas e químicas dão uma visão do momento em que elas são coletadas; portanto, é necessário um grande número de análises a fim de obter resultados robustos e confiáveis. Os resultados obtidos neste estudo e nos trabalhos de Pinto et al. (2006) demonstraram que a utilização da biota é mais eficiente do que análises físicas e químicas e que estudos subsequentes são necessários a fim de se obter resultados mais acurados.

Em função do ponto Gasômetro ter sido classificado como de alta qualidade pelo índice de qualidade integrado, em oposição aos resultados obtidos por outras metodologias que o consideram como de baixa qualidade ambiental, faz com que a utilização do IQ seja questionada no monitoramento ambiental neste tipo de ambiente, uma vez que o índice não foi eficiente para a drenagem do Lago Guaíba, uma vez que os pontos Gasômetro e Gravataí PC foram classificados como de alta qualidade e os pontos Gravataí RS118 como de média qualidade, contradizendo os resultados verificados por Flores-Lopes (2006) e Malabarba et al. (2004) para a análise de alterações morfológicas, e Flores-Lopes (2006) para análise 
Tabela 4. Valores obtidos através do Índice de Qualidade Integrado para os Rios Caí, Sinos e Gravataí. n = número de indivíduos; s = número de espécies; H' = Índice de Diversidade de Shannon-Wiener e IQ = Índice de Qualidade Integrado.

Table 4. Values obtained through the Integrated Index of Quality for the rivers Caí, Sinos and Gravataí. $n$ = number of individuals; $\mathrm{s}=$ number of species; H' $=$ Diversity Index of Shannon-Wiener and IQ = Integrated index of quality.

\begin{tabular}{|c|c|c|c|c|c|}
\hline Total & Caí & Caí-Jacuí & Sinos & Gravat. RS118 & Gravataí PC \\
\hline $\mathrm{n}$ & 992 & 3998 & 1430 & 6069 & 16899 \\
\hline $\mathrm{s}$ & 30 & 43 & 37 & 44 & 41 \\
\hline $\mathrm{H}^{\prime}$ & 2.22032 & 2.53891 & 2.66454 & 2.09127 & 1.96063 \\
\hline $\mathrm{n} / 16899$ & 0.058702 & 0.236582 & 0.08462 & 0.359134 & 1 \\
\hline $\mathrm{s} / 43$ & 0.697674 & 1 & 0.860465 & 1.023256 & 0.953488 \\
\hline H'/2.66454 & 0.833285 & 0.952851 & 1 & 0.784852 & 0.735823 \\
\hline IQ & 1.589661 & 2.189433 & 1.945086 & 2.167242 & 2.689311 \\
\hline
\end{tabular}

Tabela 5. Classificação dos pontos de amostragem dos Caí, Sinos e Gravataí de acordo com os valores do Índice de Qualidade Integrado.

Table 5. Classification of the sampling spots of the rivers Caí, Sinos and Gravataí according to the index of quality.

\begin{tabular}{lcl}
\hline \multicolumn{1}{c}{ Qualidade } & Int. classe (IQ) & \multicolumn{1}{c}{ Pontos } \\
\hline Baixa & $1.589661-1.956211$ & Caí e Sinos \\
Intermediária & $1.956212-2.322762$ & Caí-Jacuí e Gravataí RS118 \\
Alta & $2.322763-2.689313$ & Gravataí PC \\
\hline
\end{tabular}

Tabela 6. Valores obtidos para os eixos 1 e 2 na análise multivariada. Table 6. Values obtained for the axis 1 and 2 in the multivariate analisys.

\begin{tabular}{llc}
\hline & Eixo 1 & Eixo 2 \\
\hline Porcentagem & 89,3 & 94,8 \\
Autovalores & 34,2 & 2,1 \\
$\mathrm{pH}$ & $-0,516$ & 0,114 \\
$\mathrm{O}_{2}$ & 0,563 & 0,088 \\
$\mathrm{DBO}_{5}$ & $-0,501$ & 0,092 \\
Coliformes & $-0,363$ & $-0,565$ \\
Temp. & $-0,185$ & 0,807 \\
\hline
\end{tabular}

das brânquias de Astyanax fasciatus e Cyanocharax alburnus. Também contradizendo os resultados do IQ, Bendati et al. (1998) e Bendati et al. (2003) demonstraram que a margem onde está situado o ponto Gasômetro recebe um grande aporte de nutrientes que são lançados diretamente nesta região, principalmente do Rio Gravataí e dos arroios que drenam as regiões centrais de Porto Alegre. Estes autores relataram ainda que a foz deste rio é a região mais altamente contaminada, o que é indicado pela ausência de macroinvertebrados nas suas amostragens, água com restos de lixo e óleo, altos valores da demanda bioquímica de oxigênio e condutividade, e reduzida concentração de oxigênio dissolvido.

Entretanto, este índice parece ter uma melhor aplicação em córregos do que em ambientes maiores (Bruschi Jr. et al. 2000), o que pode ser verificado nos estudos de monitoramento ambiental realizados por Flores-Lopes et al. (2008), no Rio Cachoeira, no Sul da Bahia, que obtiveram resultados satisfatórios com este índice. La Point \& Fairchild (1992) relataram que, em função de alguns indivíduos encontrarem-se uniformemente distribuídos entre várias espécies, poderia dar um índice relativamente alto de diversidade, embora um habitat seja pesadamente poluído.
Estas observações salientam que os índices não são as melhores ferramentas a serem utilizadas em programas de monitoramento ambiental e reforçam a necessidade da utilização de várias metodologias diferentes a fim de se obter uma avaliação mais acurada sobre os efeitos antropogênicos que estão atuando em um determinado local. Por outro lado, Bruschi Jr. et al. (2000), Lobo et al. (2002) e Angermeier \& Davideanu (2004), salientaram que os índices multimétricos detectam uma ampla variedade de impactos humanos, incluindo impactos no regime hidrológico, configuração do habitat e interações bióticas. No estudo realizado no lago Guaíba, fica evidente que somente a utilização de índices ecológicos no monitoramento ambiental pode acarretar em avaliações errôneas a cerca da qualidade do ecossistema. Em face disto, é imprescindível a necessidade do uso de várias metodologias diferentes a fim de se realizar uma análise mais acurada sobre os efeitos antropogênicos que estão atuando em um determinado ambiente.

Barbour et al. (1999) salientaram que a avaliação da condição biológica é o meio mais efetivo de analisar impactos cumulativos de fontes de poluição, que pode envolver degradação de habitat, contaminação química, ou retirada de água. Flores-Lopes (2006) utilizou, além dos índices de diversidade, metodologias como a análise histológica de brânquias, análise da frequência de anomalias morfológicas e a adequação da análise da frequência da doença dos pontos pretos em peixes como instrumento de avaliação da qualidade ambiental a fim de realizar um diagnóstico mais consistente da integridade dos ecossistemas e quantificar o grau de deterioração destes ambientes, uma vez que é esperado que diferentes metodologias de avaliação demonstrem respostas específicas a certos fatores ambientais. A utilização dessas metodologias na avaliação da qualidade ambiental faz com que diversos tipos de respostas obtidas sejam uma importante fonte de informações da condição dos organismos no meio em que eles vivem, permitindo ao pesquisador inferir com mais certeza sobre a natureza e o tempo de exposição dos indivíduos ao agente estressor.

Os resultados deste estudo deixam evidente que as respostas obtidas por apenas uma metodologia de avaliação não são suficientes para se fazer um diagnóstico mais acurado da real situação de um ecossistema. No caso específico dos índices multimétricos, que são fortemente influenciados por fatores como o número de espécies, abundância e guildas tróficos, o resultado obtido pode nem sempre refletir a realidade da situação da qualidade ambiental naquele local. A ocorrência de espécies reconhecidamente generalistas como Astyanax fasciatus, Cyanocharas alburnus e Hyphessobrycon luetkenii na Bacia Hidrográfica do Lago Guaíba é um indicativo de ambientes de baixa qualidade, além de serem espécies que podem influenciar o resultado de índices como o Índice de Qualidade Integrado, que utiliza como um dos parâmetros para seu cálculo o número de indivíduos, o número de espécies e o Índice de Diversidade. 
Os estudos nesta área ainda são muito incipientes e novos trabalhos se fazem necessários a fim de obter uma maior compreensão sobre a grande complexidade dos ecossistemas aquáticos e das milhares de relações que envolvem estes sistemas. Neste sentido, se fazem necessárias a adequação de novas metodologias a fim de que se possa verificar um maior número de parâmetros que estão influenciando no ambiente.

As informações geradas por estes instrumentos através dos programas de monitoramento ambiental possibilitam aumentar a capacidade preventiva do sistema de gerenciamento, oferecendo condições de antecipar situações de emergência e de perigo com contaminações que possam causar a mortandade de um grande número de indivíduos de vários grupos de organismos aquáticos e acidentes que afetam a saúde de milhares de pessoas. Além disso, as informações produzidas pelo monitoramento podem ser extremamente importantes na tomada de decisões sobre as ações dos órgãos ambientais.

\section{Agradecimentos}

Os autores gostariam de agradecer a C. E. Machado, G. N. da Silva, J. F. dos Santos, T. S. Dias, A. P. S. Dufech, D. Cognato, J. F. P. Silva, J. A. Anza, J. Giora, M. A. Azevedo e V. R. Lampert por sua ajuda nos trabalhos de campo. Agradecimento especial ao $\mathrm{CNPq}$ pela bolsa de produtividade concedida à Luiz Roberto Malabarba (464545/00-5; 476821/2003-7) e a bolsa de doutorado concedida à Fábio Flores Lopes.

\section{Referências Bibliográficas}

ALLAN, J.D. \& FLECKER, A.S. 1993. Biodiversidade conservation in running waters. Bioscience, 43:32-43.

ANGERMEIER, P.L. \& DAVIDEANU, G. 2004. Using fish communities to assess streams in Romania: initial development of an index of biotic integrity. Hydrobiologia 511:65-78.

ARAÚJO, F.G. 1998a. Uso da Taxocenose de peixes como indicadora de degradação ambiental no rio Paraíba do Sul, Rio de Janeiro, Brasil. Braz. Arch. Biol. Tech. 41(3):370-378.

ARAÚJO, F.G. 1998b. Adaptação do Índice de Integridade Biótica usando a comunidade de peixes para o rio Paraíba do Sul. Rev. Bras. de Biol. 58(4):547-558.

ARAÚJO, F.G., FICHBERG, I., PINTO, B.C.T. \& PEIXOTO, M.G. 2003. A preliminary index of biotic integrity for monitoring the condition of the Rio Paraíba do Sul, Southeast Brazil. Environ. Manage. 32(4):516-526.

AZEVEDO, M. A., MALABARBA, L. R. \& BURNS, J. R. 2010. Reproductive biology and development of gill glands in the inseminating characid, Macropsobrycon uruguayanae Eigenmann, 1915 (Cheirodontinae: Compsurini). Neotropical Ichthyology. 8(1):87-96.

BARBOUR, M.T., GERRITSEN, J., SNYDER, B.D. \& STRIBLING, J.B. 1999. Rapid bioassessment protocols for use in streams and wadeable rivers: periphyton, benthic macroinvertebrates and fish. 2a ed. EPA 841-B-99-002. U.S. Environmental Protection Agency, Office of Water, Washington, D.C.

BENDATI, M.M.; SCHWARZBACH, M.S.R., MAIZONAVE, C.R.M., ALMEIDA, L.B. \& BRINGHENTI, M.L. 2003. Avaliação da qualidade da água do lago Guaíba. Subsídios para a gestão da bacia hidrográfica. ECOS Pesq. DMAE 4(7):34.

BENDATI, M.M.A., MAIZONAVE, C.R.M., OLABARRIAGA, E.D. \& ROSADO, R.M. 1998. Use of the benthic macroinvertebrate community as a pollution indicator in the Gravataí River (RS, Brazil). Verh. Internat. Verein. Limnol. 26:2019-2023.

BRASIL. Conselho Nacional do Meio Ambiente. Resolução n 357, de 18 de junho de 2005. Estabelece classificação para águas doces, salobras e salinas do Território Nacional. DOU, Brasília, DF, 30 jun. 2005
BRUSCHI Jr., W., MALABARBA, L.R. \& SILVA, J.F.P. 2000. Avaliação da Qualidade Ambiental dos riachos através das Taxocenoses de peixes. In Carvão e Meio Ambiente (Centro de Ecologia/UFRGS.). Ed. UFRGS, Porto Alegre, 1856p.

BRUSCHI Jr., W., SALOMONI, S.E., FERMINO, F.S., PEDROZO, C.S., SCHWARZBOLD, A. \& PERET, A.C. 1998. Aplicação de um índice de qualidade de águas para lagoas costeiras, RS, afetadas por despejos urbanos. Biociências 6(1):55-66.

CAIRNS, Jr. J., McCORMICK, P.V. \& NIEDERLEHNER, B.R. 1993. A proposed framework for developing indicators of ecosystem health. Hydrobiologia 263:1-144.

CETRA, M., FERREIRA, F.C. \& CARMASSI, A.L. 2009. Caracterização das assembléias de peixes de riachos de cabeceira na bacia do rio Cachoeira (sudeste da Bahia). Biota Neotrop. 9(2): http://www.biotaneotropica.org. br/v9n2/pt/abstract?article+bn01609022009.

DAJOZ, R. 1983. Ecologia geral. Vozes, Petrópolis, 472p.

FAUSCH, K.D., LYONS, J., KARR, J.R. \& ANGERMEIER, P.L. 1990. Fish communities as indicators of environmental degradation. Am. Fisheries Soc. Symp. 8:123-144.

FERREIRA, C.P. \& CASATTI, L. 2006. Integridade biótica de um córrego na bacia do alto rio Paraná avaliada por meio da comunidade de peixes. Biota Neotropica, 6(3): 1-25.

FLORES-LOPES, F., MALABARBA, L.R., PEREIRA, E.H.L. \& SILVA, J.F.P. 2001. Alterações histopatológicas em placas ósseas do peixe cascudo Rineloricaria strigilata (Hensel) (Teleostei, Loricariidae) e sua frequência no lago Guaíba, Rio Grande do Sul, Brasil. Rev. Bras. Zool. 18(3):699-709.

FLORES-LOPES, F., MALABARBA, L.R., SILVA, J.F.P. \& PEREIRA, H.L. 2002. Histologia de deformidades vertebrais em Astyanax alburnus (Hensel, 1870) (Ostariophysi: Characidae) do lago Guaíba, Rio Grande do Sul, Brasil. Comun. Mus. Ciênc. Tecnol. PUCRS, Sér. Zool. 15(1):137-155.

FLORES-LOPES, F. 2006. Monitoramento ambiental da Bacia Hidrográfica do lago Guaíba - RS - Brasil, através da utilização de diferentes metodologias aplicadas a taxocenoses de peixes. Tese de Doutorado, Programa de Pós-Graduação em Biologia Animal, UFRGS, Porto Alegre, 228p.

FLORES-LOPES, F., MIRANDA, A., PAULO, D. V., BEZERRA, L. L., FONTES, F. M. \& BRITTO, N. C. 2008. Monitoramento da qualidade ambiental do Rio Cachoeira através da análise de anomalias morfológicas, histopatológica das brânquias e fígado de peixes.Universidade Estadual de Santa Cruz, Relatório Técnico. 28pg.

GElAiN, D., FIALHO, C. B. \& MALABARBA, L. R. 1999. Biologia reprodutiva de Serrapinnus calliurus (Characidae, Cheirodontinae) do arroio Ribeiro, Barra do Ribeiro, Rio Grande do Sul, Brasil. Comun. Mus. Cien. Tecn. PUCRS, Ser. Zôo. 12:71-82.

KARR, J.R. \& DUDLEY, D.R. 1981. Ecological perspective on water quality goals. Environ. Manage. 5:55-68.

KARR, J.R. 1981. Assessment of biotic integrity using fish communities. Fisheries 6(6):21-27.

KARR, J. R. 1987. Biological monitoring and environmental assessment: a conceptual framework. Environ. Manage. 11:249-256.

KARR, J. R. \& CHU, E.W. 1999. Biological Monitoring: Essential Foundation for Ecological Risk Assessment. Hum. Ecol. Risk Assess. 3: 933-1004

LA POINT, T.W. \& FAIRCHILD, J.F. 1992. Evaluation of sediment contaminant toxicity: the use of freshwater community structure. In Sediment toxicity assessment (G.A. Burton, ed.). Lewis Publishers, Boca Raton, p.219-235.

LOBO, E.A., CALLEGARO, V.L.M. \& BENDER, E.P. 2002. Utilização de algas diatomáceas epilíticas como indicadores da qualidade da água em rios e arroios da região hidrográfica do Guaíba, RS, Brasil. EDUNISC, Santa Cruz do Sul, 127p.

MAGURRAN, A.E. 1988. Ecological diversity and its measurement. University Press, Cambridge, 179p.

MALABARBA, L.R. \& REIS, R.E. 1987. Manual de técnicas para a preparação de coleções zoológicas. $\mathrm{N}^{\circ} 36$ - Peixes. Sociedade Brasileira de Zoologia, Campinas, 14 p. 
MALABARBA, L.R., PEREIRA, E.H.L., SILVA, J.F.P., BRUSCHI Jr., W. \& FLORES-LOPES, F. 2004. Avaliação da qualidade da água através da frequência de anomalias morfológicas em peixes: estudo de caso do lago Guaíba, Rio Grande do Sul, Brasil. Comun. Mus. Ciênc. Tecnol. PUCRS, Sér. Zool. 17(2):97-128.

MARGALEF, R. 1958. Information theory in ecology. Gen. Syste. 3:36-71.

MASON, C.F. 1991. Biology of freshwater pollution. $2^{\text {nd }}$ ed. Longman Scientific \& Technical, London, 351p.

METCALFE, J. L. 1989. Biological water quality assessment of running waters based on macroinvertebrates communities: history and present status in Europe. Environ. Poll. 60:101-139.

MOLLERKE, R.O., NOLL, I.B. \& SANTO, M.A.B.E. 2002. Níveis de mercúrio em piavas (Leporinus obtusidens) e em pintados (Pimelodus maculatus) do lago Guaíba, Porto Alegre, Estado do Rio Grande do Sul, Brasil. Rev. Bras. Toxicol. 15(2):93-97.

NORRIS, R.H. \& THOMS, M.C. 1999. What is river health? Freshwater Biol. 41:197-209.

OLIVEIRA, C. L. C., FIALHO, C. B. \& MALABARBA, L. R. 2002. Período reprodutivo, desova e fecundidade de Cheirodon ibicuhiensis Eigenmann, 1915 (Ostariophysi: Characidae) do arroio Ribeiro, Rio Grande do Sul, Brasil. Comun. Mus. Cien. Tecn. PUCRS, Ser. Zool. 15(1):3-14.
PINTO, B.C.T., PEIXOTO, M.G. \& ARAÚJO, F.G. 2006. Effects of the proximity from an industrial plant on fish assemblages in the Rio Paraíba do Sul, southeastern Brazil. Neotrop. Ichthyol. 4(2):269-278.

RODRÍGUEZ-OLARTE, D., AMARO, A., CORONEL, J. \& TAPHORN, D.C.B. 2006. Integrity of fluvial fish communities is subject to environmental gradients in mountain streams, Sierra de Aroa, north Caribbean coast, Venezuela. Neotrop. Ichthyol. 4(3):319-328.

SCHIEMER, F. 2000. Fish as indicators for the assessment of the ecological integrity of large rivers. Hydrobiologia 422/423:271-278.

SCHULZ, U.H. \& MARTINS-JUNIOR, H. 2001. Astyanax fasciatus as bioindicators of water pollution of rio dos Sinos, RS, Brazil. Braz. J. Biol. 61(4):615-622.

VIEIRA, D.B. \& SHIBATTA, O.A. 2007. Peixes com indicadores da qualidade ambiental do ribeirão Esperança, Município de Londrina, Paraná, Brasil. Biota Neotrop. 7(1):http://www.biotaneotropica. org.br/v7n1/pt/abstract?article+bn01407012007 (último acesso em 27/09/2008).

WASHINGTON, H.G. 1984. Diversity, Biotic and Similarity indices. A review with special relevance to aquatic ecosystems. Wat. Res. 18(6):653-694.

ZAR, J.H. 1999. Biosestatistical analysis. 4 ed. Prentice-Hall Editora, New Jersey, 663p.

Recebido em 25/09/2009

Versão reformulada recebida em 22/11/2010

Publicado em 02/12/2010 
